\title{
¿FUE ȘUBH «LA PLUS CHÈRE DES FEMMES FÉCONDES»? CONSIDERACIONES SOBRE LA DEDICATORIA DE LAS ARQUILLAS CALIFALES DEL INSTITUTO DE VALENCIA DE DON JUAN Y DE LA IGLESIA DE SANTA MARÍA DE FITERO *
}

\author{
LAURA BARIANI \\ CES Felipe II, Aranjuez (U.C.M.)
}

\section{Introducción}

En su reciente trabajo de gran envergadura dedicado a las mujeres en al-Andalus, Manuela Marín consideraba que aquellas que «tienen un nombre propio, un apelativo personal que las extrae de la oscuridad de la historia común [...] son, como era lógico suponer, miembros de las familias reinantes o de grupos de poder [entre las cuales] están también esclavas de categoría superior, pertenecientes a esas mismas familias» ${ }^{1}$. Por lo que concierne al repertorio epigráfico andalusí, en general, la mención explícita de una mujer en una inscripción, sea ésta de carácter oficial o privado, se tiende a considerar algo excepcional, incluso contrario al protocolo, siendo lo más común en este caso enmascarar a una dama bajo alguna forma retórica, como su parentesco ${ }^{2}$. En este sentido, valga como ejemplo un texto que conmemora la construcción de un alminar en Sevilla en 478/1085, por iniciativa de «la gran señora, madre (umm ${ }^{u n}$ ) de al-Rašīd Abī l-Ḥusayn 'Ubayd Allāh hijo de al-Mu'tamid bi-Llāh» de Sevilla, que cabe identificar con la favorita de éste, I'timād ${ }^{3}$. O una inscripción, hallada en

\footnotetext{
* Este trabajo se ha desarrollado gracias a una beca postdoctoral de la Comunidad de Madrid.

${ }^{1}$ Marín, M., Mujeres en al-Andalus, Madrid, 2000, 49.

2 Por ejemplo, Gómez-Moreno, M., «Los marfiles cordobeses y sus derivaciones», Archivo Español de Arte y Arqueología, IX (1927), 4 y Marín, M., «Las mujeres en al-Andalus: fuentes e historiografia», Arabes, judias y cristianas: Mujeres en la Europa medieval, Del Moral, C. (ed.), Granada, 1993, 37-38.

${ }^{3}$ Por ejemplo, Lévi-Provençal, E., Inscriptions arabes d'Espagne, Leiden-París, 1931, núm. 32, 40-42. Sobre I'timād, ver, por ejemplo, Marín, M., Mujeres, 55-56, 344,

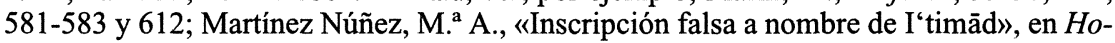
menaje al prof. Dario Cabanelas Rodríguez, O.F.M., con motivo de su LXX aniversario,
}

Al-Qanțara XXVI, 2 (2005) 299-315 
Écija, que recuerda la construcción de una fuente en 367/977-8, realizada por orden de «la señora [...], progenitora (wālidat ${ }^{u n}$ ), madre (um$m^{u n}$ ) del Príncipe de los Creyentes al-Mu'ayyad bi-Llāh Hišām, hijo de al-Hakam». La señora mencionada en el epígrafe fue una de las figuras femeninas más interesantes de al-Andalus: la favorita de al-Hakam II, Subh, quien, a lo largo de toda su vida, jugó un papel político destacado entre su hijo, el califa Hišãm II y Almanzor ${ }^{4}$. En 353/964, el «Imām y Siervo de Dios, al-Hakam» regaló a esa misma concubina uno de los más exquisitos marfiles que nos ha llegado, el llamado bote de Zamora, en cuya inscripción Șubh aparece como «la señora, madre (umm $\left.{ }^{u n}\right)$ de "'Abd al-Raḥmān», es decir el primer hijo que dio al califa, muerto prematuramente en 359/970. Sin embargo y en opinión de algunos, ése no sería el único objeto suntuario con el que al-Ḥakam II distinguiría a la mujer.

\section{Las arquillas del Instituto de Valencia de Don Juan y de la iglesia de Santa María de Fitero}

En 355/966, el maestro Jalaf talló su nombre en una pieza de marfil que estaba a punto de acabar: una diminuta cajita rectangular, cuyo cuerpo y cara superior había adornado a buril con un profundo entramado de hojas de acanto estilizadas. En los bordes de la tapa había escrito, en letra cúfica, el año de la hégira, así como el lugar en el que estaba trabajando, los talleres de Madīnat al-Zahrā'. La inscripción empezaba con la mención del nombre de Dios, a la que seguían palabras de buen augurio dedicadas al personaje de la corte a quien estaba destinado el precioso objeto.

Aunque de dimensiones más reducidas y sin que vaya firmada, en el mismo año y en el mismo lugar, se labró una pieza prácticamente

Granada, 1987, II, 261-269; Valencia, R., «Presencia de la mujer en la corte de al-Mu'tamid b. 'Abbād de Sevilla», La mujer en al-Andalus. Reflejos históricos de su actividad y categorías sociales, Viguera Molins, M. ${ }^{a}$ J. (ed.), 129-137.

${ }^{4}$ Sobre la inscripción, ver, por ejemplo, Lévi-Provençal, E., Inscriptions arabes, núm. 30, 37-38. Sobre Șubh, ver Marín, M., «Una vida de mujer: Șubḥ», en Biografias y género biográfico en el Occidente islámico, EOBA VIII, Ávila, M. ${ }^{a}$ L. y Marín, M. (eds.), Madrid, 1997, 438-445 y Bariani, L., «De las relaciones entre Șubh y Muhammad Ibn Abi 'Āmir al-Manșūr con especial referencia a su "ruptura» (waḥša) en 386́-388/996-998», Qurțuba, I (1996), 39-57. 
idéntica a la anterior ${ }^{5}$. No en vano, se la considera como obra del mismo Jalaf, o quizá de su escuela. Siglos después, a finales del XIX, esta última arquilla volvió a aparecer en los círculos del coleccionismo ${ }^{6}$. Después de pasar por distintas manos, alrededor de 1918 la pieza acabó en las de Don Guillermo Joaquín de Osma - consorte de Doña Adelaida Crooke y Guzmán, condesa de Valencia de Don Juan - y, en la actualidad, se conserva en el museo del Instituto de Valencia de Don Juan, con el número 4860 de inventario.

Por su parte, la cajita firmada por Jalaf, fue descubierta en 1923 en el Monasterio de Santa María de Fitero (Navarra), ahora iglesia parroquial, por el arqueólogo Juan Cabré. En un inventario del relicario monacal se lee que una «arquilla que es de marfil y toda de una pieza y labrada toda de relieve, que en la tapa tiene un gran rótulo arábigo», habría llegado al Monasterio en el siglo XVI, procedente probablemente de la Catedral de Pamplona ${ }^{7}$. En los bordes de la tapa de la pieza de Fitero se aprecia la inscripción:

En el nombre de Dios. Bienestar, felicidad, alegría y prosperidad

$$
\text { للاحس ولاده }
$$

\footnotetext{
${ }^{5}$ Midiendo ésta $4,5 \times 8,5 \times 5,8 \mathrm{~cm}$ frente a unas dimensiones de $12,8 \times 8,9 \times 8,3 \mathrm{~cm}$ de la otra arquilla.

${ }^{6} \mathrm{La}$ arquilla fue adquirida alrededor de 1875 por el coleccionista Argaiz. Diez años más tarde, la compró el Barón Davillier por 4000 francos, pasando en 1903 a la colección Chambière-Arlès. En 1916 la viuda de Chambière-Arlès vendió en bloque la colección al anticuario Dureen quien, en plena Primera Guerra Mundial, la envió a Estados Unidos. En cuanto a la arquilla, primero fue ofrecida a Archer Milton Huntington - fundador de la Hispanic Society of America-y luego al abuelo del conservador del Museo del Louvre, J. J. Marquet de Vasselot, sin que ninguna de las dos transacciones se llevaran a cabo. En diciembre de 1916 y por intermedio de los anticuarios parisinos M. Stora \& Cie, el marfil, que llevaría «une inscripction très importante», fue ofrecido a D. Guillermo de Osma. En otra carta de enero de 1917, los anticuarios valoraban la arquilla en 25.000 francos, precisando que «sur ce prix la difference que nous puovons vous faire ne sera pas forte» debido a que «nous trouvons cet objet très beau». Según una factura de mayo de 1917, D. Guillermo de Osma adquirió por 20.000 francos «1 coffret ivoire sculpté provenant de la collection Chabrière-Arlès ornaments et inscription au nom d'un Emir et daté de Zàhra vielle Cordue 966 de l'Ere». No obstante, en los Archivos de Valencia de Don Juan se haya una nota manuscrita de su fundador, fechada en noviembre de 1919, en la que se lee: «La apalabré con el hermano de Maurice Stora en primavera de 1917, y quedó en espera de pesetas. En oct. 1918, supe que M.[aurice] S.[tora] la había tenido en trato de cambio con M. De B. y cerré trato: y aquí está».

${ }^{7}$ La pieza fue publicada por los Sres. Albareda en 1927; Gómez-Moreno, M., «Los marfiles cordobeses», 4 y Ferrandis, J., Marfiles árabes de Occidente, Madrid, 1935, tomo I, 64; Fernández Gracia, R., El Monasterio de Fitero: Arte y Arquitectura, Pamplona, 1997, 70.
} 
Entre los objetos que se hicieron en Madīnat al-Zahrā' en el año 355 (966). Obra de Jalaf ${ }^{8}$.

La inscripción de la arquilla de Valencia de Don Juan es prácticamente idéntica a la de Fitero, salvo por la omisión de la palabra «prosperidad» (ni 'mat $\left.{ }^{u n}\right)$ y del sintagma «obra de Jalaf», lo que tal vez se explica por sus reducidas dimensiones.

Evariste Lévi-Provençal analizó ambas dedicatorias en su conocido libro Inscriptions arabes d'Espagne, llegando a la conclusión de que los dos objetos se hicieron para «la plus chère des femmes fécondes», que identificó con «la concubine d'al-Hakam II, Șubh, l'“Aurore" de Dozy, qui venait de mettre au monde le petit prince Hišăm II, à la plus grande satisfaction du calife» ${ }^{9}$. La fascinante interpretación de Lévi- Provençal sigue gozando de crédito en distintos ámbitos científicos, considerando la gran autoridad del estudioso francés y de su obra ${ }^{10}$. Cabe sin embargo destacar que del mismo pasaje existen otras interpretaciones.

\section{El destinatario de la dedicatoria}

Ya se ha señalado que tanto la arquilla de Valencia de Don Juan como la de Fitero están dedicadas al mismo personaje, tal y como se aprecia en las reproducciones que siguen.

Figura 2: Detalle de la cajita del Valencia de Don Juan

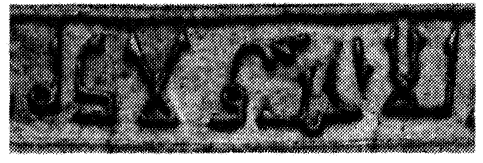

${ }^{8}$ Bi-sm $^{i}$ Llāh ${ }^{i}$. Barakat ${ }^{u n}$ min Allāh $h^{i}$ wa-yumn ${ }^{u n}$ wa-sa'ädat ${ }^{u n}$ wa-surūrun

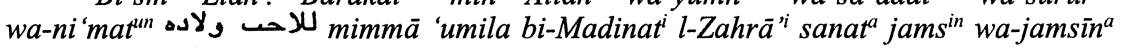
wa-talät $\underline{t}^{i}$ mi'at $^{\text {in }}$.

Se ha dejado en grafia árabe el pasaje de la inscripción en el que se menciona al destinatario de la dedicatoria, ya que será objeto de estudio.

${ }^{9}$ Lévi-Provençal, E., Inscriptions arabes, núms. 197 y 198, 187 y nota 4.

10 Marín, M., Mujeres, 318; Bariani, L., Almanzor, San Sebastián, 2003, 30 y nota 4. 
Figura 2: Detalle de la cajita de Fitero

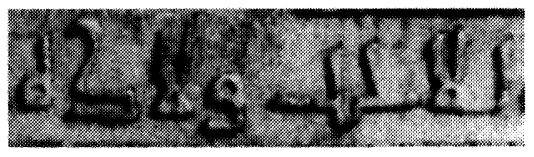

Las figuras 1 y 2 están extraídas de Kühnel E., Die islamischen elfenbeinskulpturen, Berlín, 1971, láms. IX, 24e y X, 23c.

Ambos pasajes fueron analizados en repertorios de inscripciones y estudios dedicados a objetos de marfil. Resumimos como sigue las hipótesis de trabajo a las que se acude con mayor frecuencia a la hora de tratar de los objetos en cuestión:

\section{GÓMEZ-MORENO (1927) ${ }^{11}$}

Valencia de Don Juan y Fitero

\section{Lectura del árabe Interpretación del árabe «para su amado hijo»}

\section{Personaje identificado}

«Abderrahman», el primer hijo que Subh dio a al-Hakam II

Gómez-Moreno comentó que del mismo pasaje «se han dado explicaciones distintas y menos verosímiles, leyendo "para el magnífico Walada" o "para la hermana del Califa"». Es probable que esta última interpretación sea la de Ferrandis (1928).

11 En el texto del artículo, las referencias a Gómez-Moreno, M., «Los marfiles cordobeses», Lévi-Provençal, E., Inscriptions arabes y Ferrandis, J., Marfiles árabes, se indican como los demás repertorios pormenorizados a continuación están citados según el apellido de su autor y el año de edición del estudio, es decir «Ferrandis (1928)» por Ferrandis, J., Marfiles y azabaches españoles, Barcelona, 1928; «Beckwith (1960)» por Beckwith, J., Caskets from Cordoba, Londres, 1960; «Kühnel (1971)» por Kühnel, E., Die islamischen elfenbeinskulpturen, Berlín, 1971. 


\section{FERRANDIS (1928)}

Valencia de Don Juan

$$
\begin{array}{ccc}
\text { Lectura del árabe } & \text { Interpretación del árabe } & \text { Personaje identificado } \\
\text { الاخت ولاده } & \text { «para la hermana (del Califa)» } & -
\end{array}
$$

Fitero: interpretación de Asín Palacios

$$
\begin{array}{ccc}
\text { Lectura del árabe } & \text { Interpretación del árabe } & \text { Personaje identificado } \\
- & \text { «para su dilecto hijo» } & -
\end{array}
$$

Ferrandis relata que Miguel Asín Palacios, miembro del Patronato del Instituto de Valencia de Don Juan, interpretó dicha inscripción sobre la base de un «deficiente dibujo». Considerando lo parecido de las traducciones, es muy probable que Asín Palacios discutiera de la cuestión con Gómez-Moreno, por tratarse del director del citado Instituto.

\section{LÉVI-PROVENÇAL (1931)}

Valencia de Don Juan y Fitero

$$
\begin{aligned}
& \text { Lectura del árabe Interpretación del árabe Personaje identificado } \\
& \text { لأحبّ ولاًّدة } \\
& \text { wiläda ... « «à la plus chère des naissances» }
\end{aligned}
$$

Según Lévi-Provençal también la arquilla de Valencia de Don Juan habría llevado inscrito «Obra de Jalaf».

\section{FERRANDIS (1935-40)}

Valencia de Don Juan y Fitero

$$
\begin{array}{ccc}
\text { Lectura del árabe } & \text { Interpretación del árabe } & \text { Personaje identificado } \\
\text { للاحب ولادة } & \text { «para la queridísima Walāda» } & \text { "una princesa de este } \\
\text { nombre» }
\end{array}
$$




\section{BECKWITH (1960)}

Valencia de Don Juan y Fitero

$\begin{array}{ccc}\text { Lectura del árabe } & \text { Interpretación del árabe } & \text { Personaje identificado } \\ - & \text { «for the most loved mother of } & \text { umade for the Princess } \\ \text { a son» } & \text { Subhy» }\end{array}$

\section{KÜHNEL (1971) ${ }^{12}$}

\section{Valencia de Don Juan y Fitero}

$$
\begin{array}{cc}
\text { Lectura del árabe } & \text { Interpretación del árabe } \\
\text { للاحب ولادة } & \text { "für die geliebte } \\
& \text { Walāda» }
\end{array}
$$
Interpretación del árabe «für die geliebte Walāda»
Personaje identificado «für eine Prinzessin names Walāda» ${ }^{13}$

Además de los repertorios mencionados, existen otros estudios, que se recordarán ordenados según la fecha de edición, que tratan con enfoques distintos de las dedicatorias en cuestión, refiriéndose, de forma implícita o explícita, a las hipótesis de trabajo que ya hemos reseñado. L. Torres Balbás consideró que «en la inscripción de ambas [cajitas] se nombra a una dama Walada, para la que se harían». En un estudio publicado póstumamente, el erudito local cordobés B. Montoya Tejada llegaba a la conclusión de que ambas arquillas estaban dedicadas a «la sultana Aurora», es decir a Subh. Al tratar de la arquilla de Fitero, C. Fernández-Ladreda Aguade consideró que la pieza se hizo «para la queridísima Walada», según interpretó Ferrandis (1935-40) y confirmó Kühnel (1971). Por su parte, F. Prado-Vilar, argumentaba que tanto la pieza de Fitero como la de Valencia de Don Juan estaban dedicadas a la célebre favorita de al-Hakam II, puesto que «in their respective inscriptions, Subh is called umm-walad translated as the "mother of the son" or "most loved of the fertile women"». J. Zozaya consideró que la ar-

12 Gómez-Moreno, M., «Los marfiles cordobeses», 4-5, láms. 8, 9 y 11; Ferrandis, J., Marfiles árabes, 67-69, láms. VIII-1 y VIII-2; Lévi-Provençal, E., Inscriptions arabes, núms. 198 y 197, 187 y nota 5; Ferrandis, J., Marfiles y azabaches, I, núms. 7 y 8, 61-64, láms. VII, VIII, IX, X y XI; Beckwith, J., Caskets, 14, láms. 9 y 10; Kühnel, E., Die islamischen elfenbeinskulpturen, núms. 23 y 24, 34-35, lám. X y XI.

13 Quisiera expresar mi profundo agradecimiento a Carlos Estepa Díez, director del Departamento de Historia Medieval al que me encontraba adscrita cuando realicé este estudio, por la amabilidad y paciencia que demostró en cuantas ocasiones acudí a él en busca de ayuda para comprender los matices de las traducciones y del estudio de Kühnel. 
quilla del Valencia de Don Juan se hizo «para la queridísima [um Walada (o madre fecunda de príncipe real)», mientras que la de Fitero «para la queridísima Walada». Según G. Martínez-Gros y S. Makariou, se trataría de «la plus aimée de mères», una vez más Șubh. En las fichas que dedicó a la arquilla del Valencia de Don Juan y a la de Fitero, M. Casamar consideró que se labraron «para la queridísima Walada». Por su parte, en una ficha que describe la arquilla de Valencia de Don Juan, C. Partearroyo consideró la pieza como un regalo del califa al-Ḥakam a Șubh, con ocasión del nacimiento del futuro Hišām II, de acuerdo con Lévi-Provençal. Finalmente A. Galán y Galindo, en su reciente estudio dedicado a los Marfiles medievales del Islam, opina que las dos arquillas se hicieron para celebrar el nacimiento a al-Ḥakam II de su hijo, Hišām, y traduce el pasaje de la dedicatoria como «amor persistente y nacimiento (alumbramiento) agradecido/querido», relacionándolo una vez más con Șubh ${ }^{14}$.

\section{Una lām problemática}

Llegados a este punto, parece preciso analizar las principales interpretaciones que se han ido exponiendo a lo largo de este estudio. Como ya se ha dicho, Gómez-Moreno (1927) y Asín Palacios, citado en Ferrandis (1928), tradujeron de forma muy parecida el pasaje que alude al personaje para el cual se habrían labrado las arquillas («para su amado/su dilecto hijo»). Aunque no queda constancia de sus lecturas de la inscripción cúfica, de la interpretación de ambos estudiosos se desprende que atribuyeron a los grafemas gلاد el valor de «hijo»y

14 Torres Balbás, L., «Arte califal», Historia de España dirigida por Ramón Menéndez Pidal, Madrid, tomo V, 1957, 743; Montoya Tejada, B. y Montoya Díaz, B., Marfiles cordobeses, Córdoba, 1979, 26-29 y fig. 6; Fernández-Ladreda Aguade, C., La arqueta de Leyre y otras esculturas medievales de Navarra, Pamplona, 1983, 20-24 y notas 7, 8 y 10; Prado-Vilar, F., «Circular vision of fertility and punishment: caliphal ivory caskets from al-Andalus», Muqarnas, XIV (1997), 20 y nota 9; Zozaya Stabel-Hansen, J., «Los marfiles de Cuenca», Mil Años de arte en Cuenca, Cuenca, 1999, núms. 6 y 7, 80-81; Martínez-Gros, G. y Makariou, S., «Art et politique en al-Andalus. $\mathrm{X}^{\mathrm{e}}-\mathrm{XI}^{\mathrm{e}}$ siècles», Les Andalusies, de Damas à Cordoue, Bernus Taylor, M. (ed.), París, 2000, 76-77; Casamar, M., Dos milenios en la Historia de España: año 1000. año 2000 (catálogo de exposición), Madrid, 2000, 237-238 y 245-246; Partearroyo, C., El esplendor de los Omeyas cordobeses. Catálogo de piezas, Cortés I. et al. (eds.), Granada, 2001, 252-253; Galán y Galindo, A., Marfiles medievales del Islam, tésis doctoral inédita, UNED, 2003, I, 134-146 y 400-401, y II, 571-574. Agradezco al doctor Galán y Galindo la posibilidad de consultarla. 
que consideraron el grafema $\Delta$ como el pronombre personal sufijo - hu y no como una ța $\vec{a}^{\prime}$ marbüta. Dicho pronombre se referiría al donante, si bien no mencionado en la inscripción, que Gómez-Moreno supuso que se trataba del califa al-Hakam. No en vano, en su El arte árabe español hasta los Almohades, de 1951, Gómez-Moreno parece rectificar su lectura anterior, al afirmar que la cajita de Fitero estaba «amorosamente dedicada a una dama».

En cuanto a Ferrandis (1928) y su estudio de la cajita de Valencia de Don Juan, destaca que omitió leer la preposición li-, «para». Hay que añadir que la imprecisión a la hora de interpretar la dedicatoria - «para la hermana (del Califa)»-, y sobre todo los grafemas ولاده, no permite, de momento, sacar conclusiones definitivas. Sin embargo, y aunque se tratará de ello más detenidamente, quisiera ahora hacer hincapié en que, en su repertorio de 1935-40, Ferrandis rectificó su lectura anterior, matizando و ولادة como. De hecho, ésta es la lectura más apropiada del último término del pasaje de la inscripción, el cual se puede comprender de formas diferentes según se vocalice.

Lo que acabo de exponer encuentra confirmación en el trabajo de Lévi-Provençal (1931). En efecto, el estudioso francés leyó la inscrip-

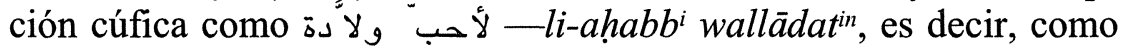
una anexión (iḍa $f a)$ - , atribuyendo al último término del sintagma el sentido de «mujer fecunda». Sin embargo, para que su hipótesis funcionara, Lévi-Provençal se vio obligado a no considerar la läm del artículo que determina el elativo $a h a b b^{u}$, si bien presente en la inscripción. El estudioso francés leyó ولادة también como wilādat ${ }^{u n}$ y de su traducción, «à la plus chère des naissances», sigue que también en este caso leyera la construcción como $l i-a h a b b^{i}$ wilädat $^{i n}$, una vez más sin considerar la lām del artículo de $a l-a h a b b^{u}$.

En cuanto a Beckwith (1960), parece que aceptó la primera lectura del árabe de Lévi-Provençal (1931). Sin embargo, según se desprende de la traducción que proporciona, es muy probable que diera al término wallädat ${ }^{u n}$ el sentido de $u m m^{u}$ walad $^{i n}$, «mather of a son», que él también identificó con Șubh.

Finalmente, Ferrandis (1935-40) y Kühnel (1971) leyeron la inscripción cúfica como للاحب ولادة, considerando ولادة (19) como el nombre propio femenino Wallādat ${ }^{\mathrm{u}}$, tratándose, según Ferrandis, de «una princesa (probablemente hermana o esposa del califa Alháquem II)». Cabe sin embargo destacar que tanto Ferrandis como Kühnel dudaron de que sus interpretaciones fuesen correctas. 
Si no cabe duda de que, tal y como nota F. Corriente, «la regla restrictiva de la formación del elativo aparece esporádicamente violada en todas las épocas» ${ }^{15}$, es igualmente cierto que, se atribuya a g ولادة el valor de wallädat ${ }^{u n}$, «mujer fecunda», o bien el del nombre propio Wallādatu, o aún el de wilādat و لادة es sintácticamente incorrecta, por lo menos en el marco del árabe clásico, puesto que en ella no hay concordancia de género entre el masculino $l i-l-a h a b b^{i}$ y el termino que sigue, el cual es femenino en todas las acepciones consideradas. Según he podido contrastar, en teoría, dicha construcción sólo se podría interpretar como $l i-l-a h a b b^{i}$ wilādat ${ }^{a n}$, «para el más querido en cuanto a su nacimiento», donde el tamyīz — wilādatan — especificaría la razón u ocasión de ser «el más querido» para el destinatario de la dedicatoria ${ }^{16}$. Si no fuera así, la construcción resultaría contraria a la sintaxis clásica del elativo, a menos de leer el árabe como لأحب ولادة, es decir como una anexión (iḍa fa) en la que la anteposición de $l i-a h a b b^{i}$ neutraliza su género. En este caso, sería posible interpretar el sintagma tanto como $l i-a h a b b^{i}$

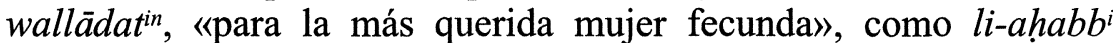
wilädat $^{\text {in }}$, «para el más querido nacimiento» $\mathrm{y}$, por un juego de acepciones, como li-ahabb ${ }^{i}$ Wallādat $^{a}$, «para la más querida Wallāda» ${ }^{17}$.

Dicho esto, y teniendo en cuenta que no siempre en las inscripciones se respetan todas las reglas ortográficas del árabe clásico ${ }^{18}$, parece que la única manera de atribuir sentido al pasaje de esta dedicatoria, es considerar la lām del artículo presente en la inscripción cúfica como un error gramatical, tal y como hizo Lévi-Provençal. Sin embargo, nos queda aún una opción.

Si bien parece que su interpretación no se ha tenido muy en cuenta - exceptuando algunos expertos en epigrafía árabe tales como M. ${ }^{\mathrm{a}} \mathrm{J}$. Ro-

15 Gramática árabe, Madrid, 1984 (3. ${ }^{\mathrm{a}}$ ed. corregida), § 144c nota 1, 245.

16 En la elaboración de este estudio he contado con el apoyo del profesor Federico Corriente, quien me ha aclarado mis numerosas dudas y a quien manifiesto mi profundo agradecimiento. También tuve la posibilidad de consultar el pasaje en cuestión con el profesor Maḥmūd 'Alī Makkī, al que agradezco su amabilidad, quien me confirmó una vez más mis ideas. Sin embargo, a propósito de la lectura $l i-l-a h a b b^{i}$ wilädat $^{a n}$ me comentó que el sintagma era sin duda correcto, aunque «no le sonaba».

17 Para las reglas gramaticales y sintáticas a las que nos hemos referido, ver por ejemplo, Blachère, R. y Gaudefroy-Demombynes, M., Grammaire de l'arabe clasique, París, 1952, § 284, \& 325 y § 289; Vecchia Vaglieri, L., Grammatica teorico-pratica della lingua araba, Roma, 1959 (4. ${ }^{a}$ ed. corregida), $\S 107, \S \S 206$ b y 207 b y $\S 595$; Corriente F., Gramática árabe, $\S 144$.

is Véase, por ejemplo, Lévi-Provençal, E., Inscriptions arabes, XXVI-XXVIII. 
dríguez y J. A. Souto ${ }^{19}$-, también Manuel Ocaña Jiménez estudió el pasaje de la dedicatoria de las arquillas del Valencia de Don Juan y de Fitero. En El cúfico hispano y su evolución de 1970, Ocaña juzgó la lectura de Lévi-Provençal (1931) —refiriéndose, con más precisión, a la primera hipótesis de trabajo de éste, لأحب" ولادة, «la plus chère de femmes fécondes»- como una «transcripción deficiente» con la que «se quiso dar a entender que dichas arquetas fueron destinadas a Subh, la cual acababa de dar a luz al futuro Hišăm II, por entonces». En efecto, Ocaña Jiménez no se conformó con las precedentes lectu-

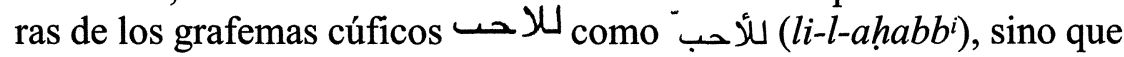
leyó en su lugar للأخت (li-l-ujti) llegando a la conclusión de que ambas arquetas se habrían hecho «para la misma dama, "la hermana Wallāda" (للأخت ولادة)», una lectura que, hasta cierto punto, había anticipado Ferrandis (1928). Sin embargo, mientras que este último no defendió su primera hipótesis de trabajo, Ocaña Jiménez no dudó en identificar a «la hermana Wallāda» con «una hermana del príncipe reinante a la sazón, al-Hakam II, e hija, por tanto, de 'Abd al-Raḥmān III, de la que los textos históricos no nos guardan noticia» ${ }^{20}$. Sin embargo, para la elaboración de El cúfico hispano y su evolución, Manuel Ocaña no pudo valerse del quinto tomo del Muqtabis de Ibn Ḥayyān, por haberse publicado en 1979. En dicha obra, Ibn Hayyãn recogió un testimonio de 'Īsà b. Ahmad al-Rāzī dedicado a los hijos de 'Abd al-Rahmān III, que deja constancia de que el califa tenía a su muerte nueve hijos varones «y entre las hembras, cinco: Saniyya, Salama, Wallāda, Hind, [y]...» ${ }^{21}$. En la misma obra se halla además un largo relato que el historiador al-Hasan b. Muhammad b. Mufarriŷ al-Qubbāšīi 22

19 «De Almanzor a Felipe II: la inscripción del Puente de Alcántara de Toledo (387/997-998) y su curiosa historia», Al-Qanțara, XXI (2000), 202, nota 49.

${ }^{20}$ Ocaña Jiménez, M., El cúfico hispano y su evolución, ..., 1970, 37 y nota 1; ver también su inscripción núm 22. Incluso este estudioso consideró que la arquilla de Valencia de Don Juan estaba firmada por el maestro Jalaf.

${ }_{21}$ Después de acabar este estudio, he tenido la posibilidad de leer el artículo «Nuevos datos para el estudio de dos piezas de eboraria califal: arquetas de la iglesia parroquial de Fitero y del Instituto Valencia de Don Juan», Anales de Historia del Arte, IX (1999), 27-33, en el que su autora, Silva Santa-Cruz, N., llegaba a «la constatación histórica de la existencia de una princesa llamada Wallada, hija de Abd al-Rahman III», basándose en la traducción de este mismo pasaje, atribuido a Ibn Hayyān, constatación que la llevó a considerar correctas las lecturas de Ferrandis, J., Marfiles y azabaches; Kühnel, E., Die islamischen elfenbeinskulpturen.

${ }^{22}$ Sobre 'İsà b. Ahmad al-Rāzī (m. siglo IV/X) y el alfaquí al-Hasan b. Muhammad b. Mufarriŷ al-Qubbāšī (m. 430/1039), ver, por ejemplo, Pons-Boigues, F., Ensayo biobi- 
dedicó a Marŷān, la conocida concubina del primer califa de al-Andalus, en el que se precisa que:

Dios dio [a 'Abd al-Raḥmān III de Marŷān] cinco de sus hijos más estimados y de posición más alta entre sus hermanos, a saber, tres nobles príncipes de los que el mayor y más sobresaliente fue Abū l-'Āṣī al-Ḥakam, primogénito y preferido de su padre y heredero suyo, y sus hermanos 'Ubaydallāh 'Abdal-'azīz, y sus hermanas, hijas asimismo de Marŷān, Hind y Wallāda ${ }^{23}$.

Dicho esto y considerando que la interpretación de Ocaña Jiménez se fundamenta epigráfica, filológica e históricamente, no parece atrevido afirmar que las arquillas de Valencia de Don Juan y de Fitero se hicieron para Wallāda, hija de 'Abd al-Raḥmān III y Marȳān, y hermana uterina de al-Hakam II y no para «la plus chère de femmes fecondes», Șubḥ.

\section{A modo de conclusión}

Los testimonios epigráficos sobre mujeres andalusíes, que han llegado hasta nosotros, son muy escasos, lo que dificulta el situar la dedicatoria de Wallāda en un contexto lo suficientemente amplio como para llevar a cabo un estudio concluyente sobre ella. De hecho, en un primer análisis, la mención tan rotunda del nombre de la «hermana Wallāda» no parece ir más allá de la excepción que confirma la regla. Con todo, y aunque sólo basándose en el sentido común, no sería extraño que en objetos destinados a los harenes se labrara el nombre de su dueña, con el objetivo, por ejemplo, de evitar que las damas que agru-

bliográfico sobre los historiadores y geógrafos arábigo-españoles, Amsterdam, 1972 (reimpresión de 1898), núm. 41, 82 y 86, 119; Una crónica anónima de 'Abd al-Rậmān III al-Nāsir, ed. y trad. Lévi-Provençal, E. y García Gómez, E., Madrid-Granada, 1950, 21-22; Imamuddin, S. M., «Sobre el autor de la "Crónica anónima de 'Abd al-Rahmān III al-Nāșir"», Al-Andalus, XXI (1956), 210-211.

${ }_{23}{ }^{\circ}$ Tal y como se ha dicho, ambos testimonios están recogidos en Ibn Hayyān, al-Muqtabas li-Ibn Hayyān al-Qurtubī (al-ŷuz' al-jämis), Chalmeta, P., Corriente, F., Șubh, M. (eds.), Madrid-Rabat, 1979, 18 y 13; trad. española de Viguera. Ma J. y Corriente, F., Cronica del califa 'Abdarrahmmān III an-Nāsirir entre los años 912 y 942, Zaragoza, 1981, 24-25 y 19.

También el emir al-Hakam I tuvo una hija que se llamó Wallāda, mientras que entre las numerosas hijas del emir 'Abd al-Rahmmān II dos llevaban este mismo nombre; Ibn Hayyān, Crónica de los emires Alhakam I y 'Abdarrahmān II entre los años 796 y 847 [Almuqtabis II-1], traducción, notas e índices de M. 'A. Makkī y F. Corriente, Zaragoza, 2001, f. 116r; Ibn Ḥayyān, al-Muqtabis min anbā' ahl al-Andalus, Makkī, M. 'A. (ed.), Beirut, 1973, 24. 
paban los gineceos llegaran a disputarse su propiedad. A este propósito cabe señalar que, tal y como leyó Manuel Ocaña Jiménez, el esenciero en plata del Museo Provincial de Teruel se hizo para «la excelsa señora Zahr, esposa del hââyib Mu'ayyad al-Dawla 'Abd al-Malik b. Jalaf» de los Banu Razīn, siendo éste el segundo monarca independiente de la taifa de Albarracín (436/1045-486/1103) ${ }^{24}$. Además, según se interpretó en unos estudios del siglo XIX, la Arqueta de San Isidoro - Museo Arqueológico Nacional- se habría hecho para una dama, leyéndose en su dedicatoria «el nombre "Sā'ida"» o la locución «para su esposa segunda Al-Badir» ${ }^{25}$. Finalmente, en uno de los fragmentos de arquetas árabes con las que se reconstruyó la parte trasera de la Arqueta de las Bienaventuranzas - Museo Arqueológico Nacional-, Francisco Simonet leyó «... regalo regalado a la señora del sultán ...» ${ }^{26}$.

Aunque parece que, con la única excepción del esenciero de plata de «la excelsa señora Zahr», las demás propuestas de lectura son muy poco defendibles, lo importante es que Wallāda no fue la única que tuvo el privilegio de ver su nombre en la inscripción de un objeto de uso privado, lo que podría llevar a reconsiderar la excepcionalidad de la dedicatoria de las arquetas de Valencia de Don Juan y de Fitero. Además, no hay que olvidar el ya mencionado bote de Zamora, en el

${ }^{24}$ Ver, por ejemplo, Almagro, M., «Una joya singular en el reino moro de Albarracín», Teruel, XXXVII (enero-junio 1967), 8 y figs. 1-12; Viguera Molins, Ma J., El Islam en Aragón, Zaragoza, 1995, 103, fig. 93; Robinson, C., "Esenciero", Al-Andalus. Las artes islámicas en España, Granada, 1992, 219. Casamar, M., «Esenciero», Dos milenios en la historia de España: año 1000, año 2000, Madrid, 238-239.

Sobre Abū Marwān 'Abd al-Malik b. Hudayl b. Jalaf b. Lubb b. Razīn de Albarracín, ver, por ejemplo, Ibn 'Id̄̄īi, Kitāb al-bayān al-mugrib fi ajbār al-Andalus wa-l-Magrib, tomo III, Lévi-Provençal, E. (ed.), París, 1930, 182-184; trad. española de Maíllo Salgado, F., La caída del Califato de Córdoba (al-Bayān al-Mugrib), Salamanca, 1993, 155-157.

${ }^{25}$ Número de inventario 51015. Amador de los Ríos, J., «Arqueta arábiga de San Isidoro de León», Museo Español de Antiguedades, Madrid, 1872, I, 61-71 y especialmente 67; Amador de los Ríos, R., «Arquetas arábigas de plata y de marfil», Museo Español de Antiguedades, Madrid, 1877, VIII, 533; Leguina, E. de, Arquetas hispano-árabes, Madrid, 1912, 66; Ferrandis, J., Marfiles y azabaches, 96-97; Galán y Galindo, A., Marfiles, II, 834-835.

${ }^{26}$ Museo Arqueológico Nacional, número de inventario 52092. Dicha reconstrucción seguramente se hizo con fecha posterior a 1063, año en el que Fernando I y su esposa Sancha donaron, por vía testamentaria a la Real Basílica de San Isidoro, la Arqueta de las Bienaventuranzas; Amador de los Ríos, J., «Arqueta de marfil de la Colegiata de San Isidoro de León», Museo Español de Antiguedades, Madrid, 1873, II, 545-559 y especialmente 553-554; Leguina, E. de, Arquetas, 46 y 76-77; Franco Mata, A., «El tesoro de San Isidro y la Monarquía leonesa», Boletín del Museo Arqueológico Nacional (1991), 35-67; Galán y Galindo, A., Marfiles, II, 632-633. 
cual Șubh aparece como «la señora, madre $\left(u m m^{u n}\right)$ de 'Abd al-Raḥmān» y que a primera vista parece desmentir lo que se acaba de decir. Sin embargo, no es así. En esta inscripción de extremo interés, Subh no aparece según su apelativo personal —que connotaba claramente el origen esclavo y extranjero de la mujer-, utilizándose en su lugar uno de los signos más distintivos del sistema onomástico árabe y en este caso seguramente expresión de su arabización e islamización, es decir su kunya Umm 'Abd al-Raḥmān. Si bien es verdad que a menudo la kunya se tiende a considerar como un «nombre oficial» o incluso un "velo», en contraposición con nombres propios, apocorísticos de tipo afectivos, etcétera, limitándose el uso de estos últimos únicamente en el seno de la familia ${ }^{27}$, éste no parece el caso del bote de Zamora por ser un objeto de uso privado. En efecto, el que en su inscripción a Șubḥ se la llame Umm 'Abd al-Raḥmān - siendo éste, se recuerda, el primer hijo que dio a al-Hakam II- parece más bien hecho a propósito para expresar el prestigio y el poder del que gozaba Subh dentro del harén por ser madre del heredero presunto al califato omeya andalusí - hasta su muerte prematura en 359/970.

Por supuesto, las inscripciones en objetos de uso privado tienen un talante diferente de aquellas fundacionales, en las que, debido a su carácter público, las mujeres son mencionadas según su parentesco. Con todo, parece preciso comentar, aunque brevemente, los epígrafes ya mencionados de I'timād (478/1085) y Șubḥ (367/977-8). En ambas inscripciones estas damas poderosas son destacadas con el título de señora - de gran señora, en el caso de I'timād - al que sigue su correspondiente kunya. I'timād es Umm al-Rašīd, siendo éste el heredero al trono de al-Mu'tamid desde el 470 , tal y como por ejemplo se manifiesta en las acuñaciones del último señor 'abbādí de Sevilla ${ }^{28}$. Por su parte, la

27 Sublet, J., Le voile du nome. Essai sur le nom prope arabe, París 1991, 40 y 191-192; Wensinck, A. J., «Kunya», EI 2 , V, 395-396; Marín, M., Mujeres, 64-70.

28 Vives y Escudero, A., Monedas de las dinastias arabigo-españolas, Madrid, 1893, serie de «Madīnat Išbiliya»: núms. 954-961; «Madīnat Qurțuba»: núms. 973-978; «Madīnat Mursiya»: núms. 979-988; Prieto y Vives, A., Los Reyes de Taifas. Estudio numismático de los musulmanes españoles en el siglo $v$ de la Hégira (XI de J.C.), edición facsímil con inclusión de las Láminas inéditas de A. Prieto y Vives y suplemento a las monedas de los reinos de taifas por Tawfíq ibn Häfiz Ibrāhìm y Alberto Canto Garcia, Madrid, 2003, serie de «Madīna Ishbīliya»: núms. 411, 412 a-k, 413 a-b, 414; segunda serie de «Madīna Qurțuba»: núms. 420 a-c, 421 a-e, 422; serie de «Madīnat Mursiya»: núms. 423 a-c, 424 a-c, 425-429; Canto García, A., Ibn Hāfiz Ibrāhīm, T., Martín Escudero, F., Monedas andalusies, Madrid, 2000, núm. 1947. 
kunya de Subh se presenta más compleja, también considerando que, por aquel entonces, su hijo Hišām acababa de subir al trono. Șubh es llamada, en efecto, Umm amìr al-mu'minin al-Mu'ayyad bi-Llāh Hišām b. al-Ḥakam. Destaca además que incluso se la llame wālida (progenitora), lo que tal vez, tal y como propuso Lévi-Provençal, podría interpretarse como otro título ${ }^{29}$. Sin embargo, lo más llamativo de esta inscripción es que a la mujer se la distinga con la frase $a^{\prime} a z z a-h \bar{a}$ Lläh (Dios le conceda gloria), al igual que a personajes de la talla del emir 'Abd al-Raḥmān II y el califa 'Abd al-Raḥmān III, lo que evidentemente denota el gran poder del que llegó a gozar Șubh ${ }^{30}$.

Otro testimonio de la intensa actividad constructora subvencionada por damas de la familia en el poder se encuentra en las fuentes literarias ${ }^{31}$. Valga como ejemplo un pasaje según el cual las concubinas y esclavas del emir 'Abd al-Rahmān II (206/822-238/852) «colaboraron, a porfía con sus guardadas esposas, en construir excelentes mezquitas en Córdoba [...] las cuales llevan sus nombres y son conocidas por ellos, como la mezquita de Țarūb, la de Fahrr, la de Aššifā', la de Mut'ah, y otras muchas similares» ${ }^{32}$. Desafortunadamente, este y otros testimonios parecidos no dejan claro si las construcciones pías, sufragadas por mujeres relacionadas con los Omeyas, eran informalmente conocidas por el nombre de su patrocinadora o si esto se debía a una inscripción que dejaba constancia del nombre o apelativo personal de aquella. Con todo, es preciso señalar una inscripción fundacional que conmemora unas obras de reforma en una mezquita de Córdoba que, entre 350/961 y 366/976, se hicieron por iniciativa de la concubina de 'Abd al-Rahmmān III, madre de su hijo menor, al-Mugī$\mathrm{ra}$, en la que la mujer no sólo aparece como madre de este último, sino también con su apelativo personal:

En el nombre de Dios, Clemente y Misericordioso [...]. La señora Muštāq, madre del hermano $\left(a l-a j^{u}\right)$ al-Mugìra, ha ordenado la construcción de este almimbar y del pasadizo que le es contiguo, así como la reestructuración de la fachada de esta mezquita $[\ldots]^{33}$.

${ }^{29}$ En la inscripción Șubh es distinguida como al-sayyidat " a 'azzahā Llä $\bar{a}^{u}$-wālidat" $u_{m m} \operatorname{amir}^{i}$ [...]; Lévi-Provençal, E., Inscriptions arabes, núm. 30, 37-38.

${ }^{30}$ Ver, por ejemplo, Lévi-Provençal, E., Inscriptions arabes, núm. 28 bis, 198; núm. 29, 38-37; núm. 39, 50-51.

31 Ver, por ejemplo, Marín, M., Mujeres, 339-344.

${ }^{32}$ Ibn Ḥayyān, Crónica de los emires, f. 142r.

33 Ver, por ejemplo, Lévi-Provençal, E., Inscriptions arabes, núm. 18, 24-26; Ocaña Jiménez M., El cúfico, 42 y núm XXVI. Sobre Muštāq véase, por ejemplo, Ibn Hayyān, 
Si por una parte llama la atención que la inscripción haga hincapié en el parentesco que unía a al-Mugĩra al califa reinante a la sazón - siendo «el hermano» al igual que Wallāda en sus dos arquillas, sin que por ello se considerara preciso mencionar también al califa al-Hakam II- , por otra y por lo que se ha podido averiguar, de momento la inscripción del nombre de Muštāq sí representa una excepción.

Sea como fuere, el de la concubina Muštāq, el de la princesa omeya Wallāda y el de Zahr de la taifa de Albarracín, constituyen tres casos patentes de divulgación de nombres de damas de épocas y de extracción social diferentes, en inscripciones tanto de carácter privado como público, por lo que sería deseable que se profundizara en el tema, tanto revisando las lecturas de las inscripciones ya identificadas, como siguiendo el rastro de los repertorios epigráficos con la esperanza de encontrar otros ejemplos parecidos, sin descuidar, por supuesto, los testimonios que proceden de otras áreas del Islam ${ }^{34}$. De este modo, tal vez se logre reunir nuevas informaciones que, contrastadas con las procedentes de las fuentes literarias, contribuyan a proporcionar un conocimiento más amplio de las mujeres relacionadas con el poder, considerando que, en general, los testimonios epigráficos proporcionan informaciones altamente fiables y plantean cuestiones de gran interés histórico.

\section{RESUMEN}

Las arquillas de marfil de época califal que se conservan en el Instituto de Valencia de Don Juan y en la iglesia de Santa María de Fitero se labraron para el mismo personaje de la corte de al-Hakam II, tal y como se evidencia de la dedicatoria escrita con grafia cúfica. Varios especialistas interpretaron el pasaje en cuestión de distintas maneras, siendo las lecturas que acabaron por gozar de ma-

al-Muqtabis li-Ibn Hayyān, 8/14-15 y Marín, M., Mujeres, 343; sobre al-Mugīra, ver Ibn Hayyān en Ibn Bassām, al-Dajīra fi mahāsin ahl al-yazizira, 'Abbās, I. (ed.), Beirut, 1981, IV/1, 58-59; Ibn 'Id̄ārī, Kitāb al-bayān al-mugrib fì ajbār al-Andalus wa-l-Magrib, Lévi-Provençal, E. y Colin, G. S. (eds.), Leiden, 1951, 251 y 260-262; Ibn Sa'īd, al-Mugrib fí hulà al-Magrib, Dayf, Š. (ed.), El Cairo, 2. ${ }^{a}$ ed., 1964, I, 200; al-Maqqarī, Nafḥ al-țîb min guṣn al-Andalus al-rațīb, 'Abbās, I. (ed.), Beirut, 1968, I, 396 y III, 86.

34 Aunque se haya llevado a cabo un vaciado muy somero en los repertorios de inscripciones orientales, se han identificado dos inscripciones fundacionales a nombre de la madre del califa abbasí al-Muqtadir bi-Llāh (295/909-320/932), el primer califa niño del Islam. 
yor crédito la de E. Lévi-Provençal — quien identificó el personaje con Șubh, concubina de al-Hakam II y madre de Hišām II-y la de J. Ferrandis y E. Kühnel - quienes leyeron en la dedicatoria «para la queridísima Wallāda», aunque sin identificar al personaje.

No obstante, el estudio filológico de la inscripción en la base de la interpretación de Manuel Ocaña Jiménez, junto al testimonio de las fuentes históricas confirman la hipótesis de que los objetos suntuarios en realidad se hicieron para la hermana uterina de al-Hakam II, Wallāda.

\begin{abstract}
Ivory caskets from the Andalusian Caliphate housed in the Instituto de Valencia de Don Juan and Santa María de Fitero's church, were worked for the same personage as their inscriptions, in Kufic alphabet, prove. Scholars have interpreted those passages in quite different ways though the most credited lectures are Lévi-Provençal's - who identified the personage with Șubh, concubine of al-Hakam II and mother of Hišăm II - and Ferrandis' and Kühnel's - both of them read in the inscription «to the beloved Wallãda» - although they did not identify the personage- .

Nevertheless, the philological analysis of those inscriptions underlying the interpretation made by Manuel Ocaña Jiménez and the existing historical sources, confirm the hypothesis of those luxury objects being worked for another member of the court, the uterine sister of al-Hakam II, Wallāda.
\end{abstract}

